\title{
Learning progressions as models and tools for supporting classroom assessment
}

\author{
Associate Professor Alicia C Alonzo \\ Michigan State University \\ https://doi.org/10.37517/978-1-74286-638-3_5
}

Alicia Alonzo, PhD, is an Associate Professor in the Department of Teacher Education at Michigan State University. Her research agenda is centred around the premise that assessment - broadly construed - has the potential to exert a significant influence on both student and teacher learning. Her work considers assessment practices at both the classroom level (as teachers use interactions with students to tailor instruction and generate professional knowledge) and at the large-scale level (as state, national, and international assessments signal what is valued as learning in science classrooms). Much of Alicia's research has focused on tools (learning progressions) and knowledge (pedagogical content knowledge) underlying classroom assessment practices.

\section{Abstract}

Like all models, learning progressions (LPs) provide simplified representations of complex phenomena. One key simplification is the characterisation of student thinking in terms of levels. This characterisation is both essential for large-scale applications, such as informing standards, but potentially problematic for smaller-scale applications. In this paper, I describe a program of research designed to explore the smaller-scale use of LPs as supports for teacher classroom assessment practices in light of this simplification. Based on this research, I conclude that LP levels may serve as a generative heuristic, particularly when teachers are engaged with evidence of the limitations of LP levels and supported to use LPs in ways that are not reliant on these levels.

\section{Introduction}

Like all models, LPs provide simplified representations of a complex phenomenon (e.g. Lehrer \& Schauble, 2015), capturing some features of students' thinking and learning but necessarily simplifying others. As Leher and Schauble (2015) caution:

It is imperative to remember that an LP is a model ... Like all models ... LPs are incomplete and even incorrect in some respects ... The question to ask about [LPs] is not 'Are they true?' but rather, 'Are they useful for the purposes that we need them to achieve?' (p. 435).

In other words, as with scientific models, LPs should be evaluated not just in terms of empirical adequacy but also in terms of criteria such as utility and generativity (Odenbaugh, 2005) with respect to proposed use.

The purposes proposed for LPs include both large-scale applications - informing standards (Foster \& Wiser, 2012), curricula (Songer et al., 2009), and large-scale assessment (Alonzo et al., 2012)-and those at a smaller-scale - informing instruction (Scott et al., 2019) and classroom assessment (Furtak, 2012). While large-scale uses rely on the broad characterisation of student thinking into LP levels, this simplification may be problematic for smaller-scale uses of LPs (Alonzo \& Elby, 2019; Alonzo et al., 2021). In particular, what underlies common approaches to validation is the assumption that student thinking is coherent and consistent. LPs are evaluated according to the criterion of 'conceptual coherenc[e]' (Anderson, 2008, p. 4) and using assessments that rely on the assumption 
that student thinking is consistent enough to be reliably characterised using LP levels. However, research suggests that student ideas have context-dependencies that do not fit neatly into LP levels (Heredia et al., 2012) and that the conceptual territory between the upper and lower anchors of an LP (the 'messy middle'; Gotwals \& Songer, 2010, p. 277) may be particularly fragmented and contextdependent (Steedle \& Shavelson, 2009).

To support classroom assessment, LPs have been proposed to focus attention on student ideas that might be important to elicit, support interpretation of the ideas that are elicited, and inform responses to those ideas (Alonzo, 2018). A basic model for this use focuses on determining students' LP levels and using those levels to identify instructional next steps that will support incremental movement towards the targeted level of understanding (Covitt et al., 2018). However, diagnosing and responding based on LP levels is complicated by the uncertainty (and, thus, unreliability) introduced by the context-dependency and inconsistency of students' thinking.

In this paper, I describe a series of studies designed to support teacher use of LPs to support classroom assessment practices, with particular attention to a) how LPs might have utility and generativity for this purpose despite the simplification of LP levels and $b$ ) how LPs might be used without relying on this simplification.

\section{Research program}

In order to explore the usefulness of LPs as supports for teachers' classroom assessment practices, particularly in light of the simplified representation of student thinking in levels, we undertook a series of five related studies (depicted in Figure 1). The first four are discussed.

Figure 1 Relationship between five studies comprising research program on teacher use of LPs to support classroom assessment practices

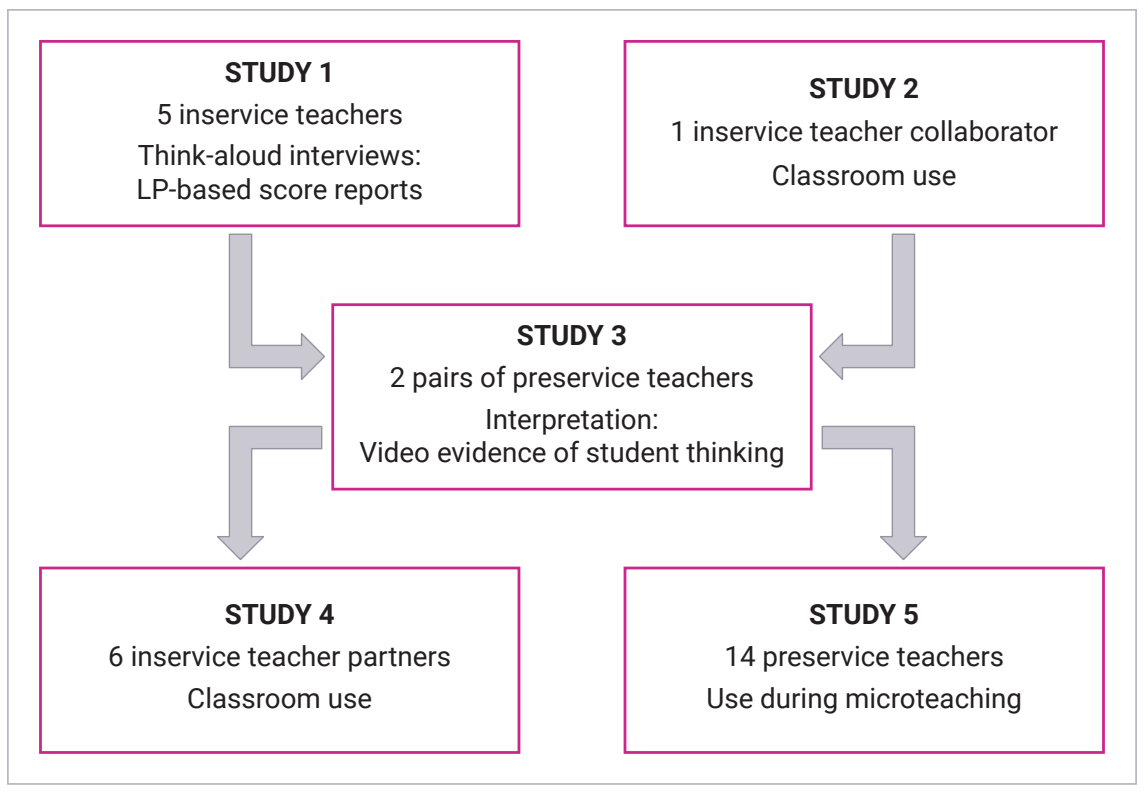




\section{Study l: Inservice teachers' engagement with LP-based score reports}

Study 1 (Alonzo \& Elby, 2019) involved five experienced high school physics teachers with highquality formative assessment practices (based on researcher recommendation and verified using an initial interview). The teachers interacted with an LP-based score report in a set of two thinkaloud interviews. The score report presented LP-based assessment results for a fictitious, but realistic, class of students. We examined: a) the assumptions about student thinking that teachers made as they engaged with the score reports and the instructional reasoning supported by different assumptions and $\mathrm{b}$ ) ways that teachers developed (or could develop) new understandings based on their engagement with the score report.

We found that teachers understood the general intent of the LPs and appropriated language from the LP-based materials to reason about student thinking. However, they more frequently treated student thinking as less coherent than the LP perspective suggested and offered finer-grained interpretations than those provided by LP levels. The only specific, actionable instructional responses that teachers proposed were based on these finer-grained analyses. Teachers generated knowledge about student thinking by taking a sceptical stance towards the LP and investigating places where the LP model did not adequately explain the data.

\section{Study 2: Inservice teacher collaborator's use of LPS}

Study 2 (Alonzo, 2019; Alonzo \& Elby, 2019) focused on one teacher from Study 1 who collaborated with (and participated as member of) the research team. 'Tim' used the LPs to inform his classroom assessment practices, serving as a check of the laboratory-based results obtained in Study 1.

Tim used the LP levels to fulfill a requirement that he report pre-/post-test gains for his students, highlighting that level-based interpretations permitted him to demonstrate growth even when students had not met the learning targets. However, he did not find the levels useful for informing his own classroom assessment practices; instead, as in Study 1, he used LP-based assessment results as a springboard for inquiry into his students' ideas.

\section{Study 3: Preservice teachers' use of LPs to interpret video evidence of student thinking}

In Study 3 (von Aufschnaiter \& Alonzo, 2018), we added a short introduction (150 minutes) to a LP to a methods course for preservice physics teachers. Using a pre- and post-design, we compared how two pairs of teachers interpreted evidence of student thinking presented in videos of cognitive interviews with and without the LP.

We found that the LP seemed to support the teachers in attending to specific aspects of students' thinking highlighted in the LP, in avoiding speculative or unwarranted interpretations, and in thinking about implications for future learning in more student-centred ways. At the same time, we cautioned that preservice teachers may over-apply LP frameworks - for example, attending only to ideas represented in the LP or assuming that students who hold one idea at a given LP level hold all ideas at that level. 


\section{Study 4: Inservice teachers' use of LPs to support classroom assessment practices}

In Study 4 (Alonzo et al., 2021), we supported six high school physics/physical science teachers over two years to incorporate LPs into their classroom assessment practices. Through two summer workshops and support via planning meetings during the ensuing academic years, we introduced the LP model (and three specific LPs) and highlighted ways that student thinking is more complex than is represented in LP levels. Instead of prescribing how we thought teachers should use LPs, we encouraged teachers to take up these tools in ways that made sense to them.

We found that teachers' LP use varied - from completely reliant on LP levels (e.g. reporting student performance using LP levels) to not using LP levels at all (e.g. attending to ideas on the LP without attention to levels). However, the uses that were less reliant on LP levels were more prevalent, and teachers described challenges in using LP levels - for example, students' held ideas at different LP levels, which complicated level-based interpretations. While some of the teachers' challenges may be related to models of thinking and learning inconsistent with the more constructivist assumptions of the LPs, we concluded that teacher use of LPs represented a rational response to level-based challenges.

\section{Conclusion}

Although teachers in our studies used LP levels to elicit, interpret, and respond to student ideas, these uses appeared challenging and were not prevalent. Teachers more often - and seemingly more productively - used LPs in ways that considered student ideas more closely (e.g. attended to individual ideas within an LP level, rather than the level as a coherent whole) and/or did not attend to LP level. We viewed this as a reflection of the potential issues with LP levels, particularly in relation to the inconsistency of student thinking that teachers observed (both in their own students and in the evidence we provided to them).

At the same time, the basic model of diagnosing students' LP levels and using those diagnoses to identify appropriate instruction seems to serve as a useful heuristic and jumping off point for teacher investigations of student thinking and of ways LPs might be useful to them. In this way, LPs (with their levels) appear to be a productive site for teachers' generation of knowledge-of-practice (Cochran-Smith \& Lytle, 1999). At the same time, teachers used LPs in ways that did not rely on LP levels but that did reflect an 'LP approach' - focusing on student ideas and how they can be supported to change gradually over time. Especially because researcher-developed LPs do not exist for all topics in the $\mathrm{K}-12$ curriculum, this more general approach may be an important way that LPs can impact instructional practice even if their levels do not support strict diagnoses and prescriptions for instructional 'next steps.'

\section{References}

Alonzo, A. C. (2018). An argument for formative assessment with science learning progressions. Applied Measurement in Education, 31, 104-112.

Alonzo, A. C. (2019). Defining trustworthiness for teachers' multiple uses of classroom assessment results. In S. M. Brookhart \& J. H. McMillan (Eds.), Classroom assessment and educational measurement (pp. 120-145). Routledge.

Alonzo, A. C., \& Elby, A. (2019). Beyond empirical adequacy: Learning progressions as models and their value for teachers. Cognition and Instruction, 37, 1-37. 
Alonzo, A. C., Neidorf, T., \& Anderson, C. W. (2012). Using learning progressions to inform large-scale assessment. In A. C. Alonzo \& A. W. Gotwals (Eds.), Learning progressions in science: Current challenges and future directions (pp. 211-240). Sense Publishers.

Alonzo, A. C., Wooten, M. M., \& Christensen, J. A. (2021). Teachers' perceived uses of learning progressions to inform classroom assessment and related practices [Manuscript submitted for publication].

Anderson, C. W. (2008, February). Conceptual and empirical validation of learning progressions. Consortium for Policy Research in Education. http://www.cpre.org/ccii/images/stories/ccii_pdfs/ learning\%20progressions\%20anderson.pdf

Cochran-Smith, M., \& Lytle, S. L. (1999). Relationships of knowledge and practice: Teacher learning in communities. Review of Research in Education, 24, 249-305.

Covitt, B., Gunckel, K. L., Syswerda, S., \& Caplan, B. (2018). Teachers' use of learning progressionbased formative assessment in water instruction. Applied Measurement in Education, 31, 128-142.

Foster, J., \& Wiser, M. (2012). The potential of learning progression research to inform the design of state science standards. In A. C. Alonzo, \& A. W. Gotwals (Eds.), Learning progressions in science: In science: Current challenges and future directions (pp. 435-460). Sense Publishers.

Furtak, E. M. (2012). Linking a learning progression for natural selection to teachers' enactment of formative assessment. Journal of Research in Science Teaching, 49, 1181-1210.

Gotwals, A. W., \& Songer, N. B. (2010). Reasoning up and down a food chain: Using an assessment framework to investigate students' middle knowledge. Science Education, 94, 259-281.

Heredia, S., Furtak, E. M., \& Morrison, D. (2012, March 25-28). Item context: How organisms used to frame natural selection items influence student response choices. [Paper presentation]. NARST annual international conference, Indianapolis, IN, United States.

Lehrer, R., \& Schauble, L. (2015). Learning progressions: The whole world is NOT a stage. Science Education, 99, 432-437.

Odenbaugh, J. (2005). Idealized, inaccurate, but successful: A pragmatic approach to evaluating models in theoretical ecology. Biology and Philosophy, 20, 231-255.

Scott, E. M., Wenderoth, M. P., \& Doherty, J. H. (2019). Learning progressions: An empirically grounded, learner-centered framework to guide biology instruction. CBE-Life Sciences Education, $18,1-11$.

Songer, N. B., Kelcey, B., \& Gotwals, A. W. (2009). How and when does complex reasoning occur? Empirically driven development of a learning progression focused on complex reasoning about biodiversity. Journal of Research in Science Teaching, 46, 610-631.

Steedle, J. T., \& Shavelson, R. J. (2009). Supporting valid interpretations of learning progression level diagnoses. Journal of Research in Science Teaching, 46, 699-715.

von Aufschnaiter, C., \& Alonzo, A. C. (2018). Foundations of formative assessment: Introducing a learning progression to guide preservice physics teachers' video-based interpretation of student thinking. Applied Measurement in Education, 31, 113-127. 